\title{
Assessment of Gap between Knowledge and Practices among Type 2 Diabetes Mellitus Patients at a Tertiary-Care Hospital in Bangladesh
}

\author{
Farzana Saleh, ${ }^{1}$ Ferdous Ara, ${ }^{2}$ and Fadia Afnan ${ }^{3}$ \\ ${ }^{1}$ Department of Community Nutrition, Bangladesh University of Health Sciences, 125/1 Darus Salam, \\ Mirpur 1, Dhaka 1216, Bangladesh \\ ${ }^{2}$ BRAC Institute of Global Health, BRAC University, icddr,b Campus, 68 Shaheed Tajuddin Ahmed Sharani, \\ Mohakhali, Dhaka 1212, Bangladesh \\ ${ }^{3}$ Shopner Desh, House 56, Road 1, Banani, Dhaka 1213, Bangladesh \\ Correspondence should be addressed to Farzana Saleh; farzanasaleh_sumona@yahoo.com
}

Received 20 November 2015; Revised 6 February 2016; Accepted 10 February 2016

Academic Editor: Bernard Cheung

Copyright (c) 2016 Farzana Saleh et al. This is an open access article distributed under the Creative Commons Attribution License, which permits unrestricted use, distribution, and reproduction in any medium, provided the original work is properly cited.

Newly diagnosed type 2 diabetes (T2 DM) patients who do not receive diabetes education (DE) have average knowledge on DM, and their practices about diabetes need to be improved. This prompted us to evaluate what happens when old diagnosed patients receive DE. The study therefore assessed the association between knowledge and practices in terms of Hemoglobin $\mathrm{A}_{1} \mathrm{c}\left(\mathrm{Hb}_{1} \mathrm{c}\right)$, body mass index (BMI), and waist circumference (WC) among 500 diagnosed T2 DM using a cross-sectional design. An intervieweradministered questionnaire was used for assessing their knowledge. The mean knowledge score of the patients was $15.29 \pm 3.6$. A significant negative association was found between the knowledge score and the $\mathrm{HbA}_{1} \mathrm{c}$ level. Age was positively associated with $\mathrm{HbA}_{1} \mathrm{c}$ and WC. Duration of DM was positively and education was negatively associated with $\mathrm{HbA}_{1} \mathrm{c}$. Gender was negatively associated with BMI while income was positively associated with BMI and WC. All the associations were significant. The diagnosed T2 DM patients are deficient of sufficient knowledge; the knowledge score and $\mathrm{HbA}_{1} \mathrm{c}$ have a significant negative relationship, not other actions. The risk factors for the patients' outcome include old age, female gender, years of education, economic status, and duration of DM.

\section{Introduction}

The Southeast Asia region will see the largest number of patients with type 2 diabetes (T2 DM) within 2030, if preventive measures were not taken [1]. Diabetes is characterized by a state of chronic hyperglycemia resulting from several environmental and genetic etiologies acting jointly [2]. Until a decade ago, diabetes was not considered a major publichealth problem in developing countries like Bangladesh. However, the situation has now been changed dramatically. In Bangladesh, a higher prevalence of diabetes was found among urban population (8.1\%) than among rural population (2.3\%) [3].

Unless preventive measures are taken, Bangladesh is likely to see the outbreak of diabetes soon. Experience suggests that knowledge-based education for diabetes patients in Bangladesh may be the feasible strategy to improve selfmanagement of the disease. Results of a study showed that newly diagnosed diabetes patients who did not get any structured diabetes education from the healthcare center had an average knowledge on DM, although their self-care practices were inappropriate [4]. Another study [5] showed that the nondiabetes respondents had average awareness regarding risk factors of diabetes and the study recommended that diabetes education and sociodemographic factors need to be considered to improve the awareness in general population.

Knowledge is a prerequisite for individuals and communities for the prevention, treatment, and control of chronic diseases including diabetes [6-12]. Although the importance of self-management in diabetes is well established, little is known about the factors that encourage individuals to take an active and responsible role in this aspect [8-10]. 
A few years back, education was not even considered part of treatment. However, the importance of education is gradually increasing due to the present epidemic nature of diabetes. Proper education and guidance on diabetes care can make significant improvements in patients' lifestyle, which may help achieve the desired health outcomes [6, 7]. Knowledge acquired through culturally oriented diabetes education programs can create awareness and understanding of the disease among patients. This awareness and understanding can strengthen motivation and self-care, improve the clinical outcomes, and reduce the cost of treatment of diabetes by preventing complications. In addition, deficiency in knowledge of diabetes patients may be one of the obstacles to developing an active and dependable role in their selfmanagement of the disease.

The above context prompted us to conduct the present study to assess the association between the knowledge and the practices in terms of Hemoglobin $\mathrm{A}_{1} \mathrm{c}\left(\mathrm{HbA}_{1} \mathrm{c}\right)$, body mass index (BMI), and waist circumference (WC) among T2 DM patients who attended a structured diabetes education (DE) program in a tertiary-care hospital in Bangladesh and also to identify the risk factors those responsible in patients' outcome.

\section{Materials and Methods}

Without any comparison group and any intervention, this study was undertaken to assess the knowledge-action gap among diagnosed T2 DM patients. Using the cross-sectional design, 500 T2 DM patients who were registered at the Outpatient Department (OPD) of Bangladesh Institute of Research \& Rehabilitation in Diabetes, Endocrine and Metabolic Disorders (BIRDEM), the tertiary-care hospital of the Diabetic Association of Bangladesh, were enrolled. The minimum required sample size for the study was calculated using the following formula: $n=z^{2} p q / d^{2}$ (where, $z=1.96, p$ is the expected proportion of correct basic knowledge among diabetes patients, that is, $66 \%[4], q=(1-p)$, and $d$ is allowable error of known prevalence, that is, 5\%). And convenient sampling technique was used. Patients who were aged over 25 years, had diabetes for at least two years, and attended a minimum of one education class were included in the study. Patients who had other medical complications or were unable to answer a short list of simple questions (sociodemographic information, such as name, address, and disease-related complications) were excluded.

A method that has been used in various studies in different countries [13-15] was adapted for this study to assess the knowledge of patients. A medium-size threepart interviewer-administered questionnaire was designed to know and assess the level of patients' knowledge. The first part of the questionnaire was planned to cover information on age, sex, educational qualification, occupation, monthly income, duration of diabetes, and family history relating to diabetes. The second part covered data relating to weight, height, WC, and $\mathrm{HbA}_{1} \mathrm{c}$. The third part consisted of 35 questions on knowledge relating to fundamental understanding of diabetes, target age for blood glucose testing, benefits of exercise, hyperglycemia, groupings of foods and their exchange list, ideal body weight, and ketoacidosis. During analysis of data, we did not divide the knowledge questions into basic and technical sections like the earlier study [4] due to the differences in patient criteria.

The Diabetes Knowledge Questionnaire, validated by the University of Michigan [16], was modified following the local guidelines of the Diabetic Association of Bangladesh [17] and considering the local context, culture, and food habits of our patients. This questionnaire was translated to Bangla separately by two independent translators who were native speakers of the target language (Bangla); two separate back translations were also done by translators who were native speakers of English.

Practices of the study patients were assessed as their current glycemic report, BMI, and WC values after getting education from healthcare providers. The questionnaire was pretested before its finalization. Each correct response was assigned a score of 1 , and each incorrect response was assigned a score of 0 . Thus, for 35 items for knowledge, the maximum attainable score was 35 , and the minimum score was 0 . The level of knowledge was classified according to each respondent's score. Poor knowledge corresponded to a score $<$ mean -1 SD; average knowledge corresponded to a score within mean $\pm 1 \mathrm{SD}$; good knowledge corresponded to a score $>$ mean +1 SD [6].

Anthropometric measurements included weights, heights, and WC of the patients. A flexible tape was used for measuring WC from midway between the lowest rib and the iliac crest. A Soehnle mechanical weighing scale (SoehnleWaagen GmbH \& Co. KG, Wilhelm-Soehnle-Strabe 2, D-71540 Murrhardt/Germany) was used for measuring their body weights in light clothes to the nearest $0.1 \mathrm{~kg}$. A portable, locally manufactured stadiometer was used for measuring heights to the nearest $0.5 \mathrm{~cm}$, with subjects standing upright on a flat surface without shoes and the back of the heels and the occiput on the stadiometer. The $\mathrm{HbA}_{1} \mathrm{c}$ report was collected from the patients' medical records.

The patients were grouped according to the 2006 percapita Gross National Income (GNI) and the World Bank calculations [18] as follows: low-income group: $\mathrm{Tk}<5360$; lower-middle-income group: Tk 53610-21270; upper-middleincome group: Tk 21271-65761; and high-income group: Tk > 65762.

The SPSS software (version 17.0) (SPSS, Inc., Chicago, IL, USA) was used for analyzing data. Descriptive statistics were used for analyzing and summarizing data as follows: sociodemographic characteristics, diabetes knowledge, and practices of patients. Multivariable linear regression was used for identifying the factors which influence the practices. For regression model, $\mathrm{HbA}_{1} \mathrm{c}, \mathrm{BMI}$, and $\mathrm{WC}$ were used as dependent variables. The independent variables included age, sex, years of education, occupation, monthly income, duration of diabetes, family history of diabetes, and total knowledge score relating to diabetes. Statistical tests were considered significant at $p$ value of $\leq 0.05$.

Written consent was obtained from all the patients after full explanation of the nature and purpose of all the study procedures to them. The ethical committee of the Diabetic Association of Bangladesh approved the study. 
TABLE 1: Characteristics of patients $(n=500)$.

\begin{tabular}{|c|c|}
\hline Characteristics & No. $(\%)$ \\
\hline Age (years) $($ mean $\pm S D)$ & $49.40 \pm 8.9$ \\
\hline \multicolumn{2}{|l|}{ Sex } \\
\hline Male & $290(58)$ \\
\hline Female & $210(42)$ \\
\hline \multicolumn{2}{|l|}{ Habitat } \\
\hline Urban & $411(82)$ \\
\hline Semiurban & $76(15)$ \\
\hline Rural & $13(3)$ \\
\hline \multicolumn{2}{|l|}{ Education } \\
\hline Illiterate & $44(9)$ \\
\hline Primary-secondary & $227(45)$ \\
\hline Higher secondary-graduate & $164(33)$ \\
\hline Postgraduate & $65(13)$ \\
\hline \multicolumn{2}{|l|}{ Occupation } \\
\hline Service & $148(30)$ \\
\hline Business & $114(23)$ \\
\hline Homemaker & $181(36)$ \\
\hline Others (unemployed, laborers, and farmer) & $57(11)$ \\
\hline \multicolumn{2}{|l|}{ Family income (Tk) } \\
\hline Low-income group $(\leq 5360)$ & $84(17)$ \\
\hline Lower-middle-income group (5361-21270) & $246(49)$ \\
\hline Upper-middle-income group (21271-65761) & $131(26)$ \\
\hline High-income group (>65661) & $20(4)$ \\
\hline Body mass index (mean $\left.\pm \mathrm{SD}, \mathrm{kg} / \mathrm{m}^{2}\right)$ & $25.59 \pm 3.9$ \\
\hline Underweight $(<18.5)$ & $6(1)$ \\
\hline Acceptable risk (18.5-23) & $128(26)$ \\
\hline Increased risk (23-27.5) & $231(46)$ \\
\hline High risk $(\geq 27.5)$ & $135(27)$ \\
\hline Missing & $19(3)$ \\
\hline $\mathrm{HbAl}_{\mathrm{c}}(\%$, mean $\pm \mathrm{SD})$ & $8.3 \pm 1.7$ \\
\hline Waist circumference $(\mathrm{cm}$, mean $\pm \mathrm{SD})$ & $90.9 \pm 9.4$ \\
\hline Knowledge score $($ mean \pm SD) & $15.3 \pm 3.6$ \\
\hline
\end{tabular}

$\mathrm{US} \$ 1=\mathrm{Tk} 80$.

\section{Results}

Table 1 presents the characteristics of the 500 patients. Their mean $( \pm S D)$ age was $49.40 \pm 8.9$ years. Of the patients, $42 \%$ were female. Eighty-two percent were urban patients. Fortyfive percent had primary to secondary level of education, and $33 \%$ completed higher secondary and graduation. Thirty-six percent were homemakers, and 30\% were service holders. Forty-nine percent belonged to the lower-middle-income group. The mean $\left[( \pm \mathrm{SD})\right.$ BMI $\left.\left(\mathrm{kg} / \mathrm{m}^{2}\right)\right]$ was $25.5 \pm 3.9$, and $46 \%$ were at increased risk group and $26 \%$ were at acceptable risk [19]. The mean $( \pm \mathrm{SD}) \mathrm{HbA}_{1} \mathrm{c}(\%)$, WC $(\mathrm{cm})$, and duration (years) of diabetes were $8.3 \pm 1.7,90.9 \pm 9.4$, and $7.9 \pm 6$, respectively. The total knowledge score (mean \pm SD) of the patients was $15.3 \pm 3.6$.

Table 2 presents the patients' deficiencies in diabetes knowledge. Most (81\%) patients had knowledge on definition of DM, although $98 \%$ were unaware of risk factors. Over one-third (35\%) could not give correct answer about the normal blood glucose level, $60.2 \%$ had no knowledge about hypos, $91 \%$ had no concerns about ketoacidosis, and $23 \%$ were unaware of the principles of dietary management of DM. Most (97\%) patients had no idea about the food-exchange system. About $81 \%$ did not know the basic rules of foot care.

No significant association was found among the knowledge score, BMI $(r=0.007, p=0.87)$, and WC $(r=0.042$, $p=0.345)$ of the patients. However, a significant negative association was found between the knowledge score and the $\mathrm{HbA}_{1}$ c level $(r=-0.106, p=0.017)$ (Table 3).

To identify the factors that might have effects on the patients' $\mathrm{HbA}_{1} \mathrm{c}, \mathrm{BMI}$, and $\mathrm{WC}$ values, multivariable linear regression analyses were performed. All the eight parameters, age, sex, years of education, occupation, monthly income, duration of diabetes, family history of diabetes, and total knowledge score relating to diabetes, were included simultaneously in the regression model. The results showed that the overall multiple regression model used for assessing the factors of $\mathrm{HbA}_{1} \mathrm{c}$ achieved $R^{2}$ of $0.032 ; p=0.004$. Age $(p=$ 0.02 ; 95\% CI: $0.076-0.867)$, education ( $p=0.014$; $95 \% \mathrm{CI}$ : $0.503-0.056)$, and duration of DM ( $p=0.002$; 95\% CI: $0.830-$ $0.195)$ were significantly associated with the $\mathrm{HbA}_{1} \mathrm{c}$ value after adjustment (Table 4).

Regression analysis also identified significant predictors of patients' BMI $\left(R^{2}=0.064 ; p=0.0001\right)$. The female patients had a higher BMI $(p=0.005$; 95\% CI: $2.743-$ 0.505). The upper-middle income and high-income groups of patients were at increased risk or at high risk of overweight and obesity ( $p=0.02$; 95\% CI: 0.090-1.049) (Table 5).

Results of regression analysis showed significant determinants of patients' WC $\left(R^{2}=0.029 ; p=0.006\right)$. Age $(p=$ 0.002 ; 95\% CI: 5.719-1.262) and monthly income ( $p=0.004$; 95\% CI: 0.552-2.91) were significantly associated with WC after adjustment (Table 6).

\section{Discussion}

Various studies have emphasized knowledge on DM as an important resource to guide and educate diabetes patients about their practices [6-11]. It has been recognized that health promotion, based on common knowledge and perceptions regarding chronic diseases such as diabetes, is an essential component of any strategy aimed at disease control and prevention. In previous studies $[4,5]$, subjects did not get any structured education on diabetes from their healthcare centers. As a consequence, an average level of knowledge on and understanding of diabetes was found among them, and their self-care practices were also found to be inappropriate. Considering the above fact, the present study was initiated among those patients who received culturally appropriate structured education on diabetes from a tertiary-care hospital of the Diabetic Association of Bangladesh. The study assessed the association between knowledge and practices in terms of $\mathrm{HbA}_{1} \mathrm{c}, \mathrm{BMI}$, and $\mathrm{WC}$ among old diagnosed T2 DM patients attending a tertiary care hospital in Bangladesh.

The present study has shown that only $73.4 \%$ of the patients had an average knowledge on DM whereas about 
TABLE 2: Identified deficient knowledge areas relating to DM among patients $(n=500)$.

\begin{tabular}{|c|c|c|}
\hline Knowledge on diabetes & $\begin{array}{c}\text { Correct answer } \\
\text { number }(\%)\end{array}$ & $\begin{array}{c}\text { Incorrect answer } \\
\text { number }(\%)\end{array}$ \\
\hline Definition of diabetes & $405(81)$ & $95(19)$ \\
\hline Risk factors of diabetes & $10(2)$ & $490(98)$ \\
\hline Targeted level of blood glucose & $325(65)$ & $175(35)$ \\
\hline Knowledge on hypoglycemia & $199(39.8)$ & $301(60.2)$ \\
\hline Knowledge on ketoacidosis & $45(9)$ & 455 (91) \\
\hline Principles of dietary management & $387(77)$ & $113(23)$ \\
\hline Food exchange system for dietary management & $16(3)$ & $484(97)$ \\
\hline Basic rules of foot care & $96(19)$ & $404(81)$ \\
\hline
\end{tabular}

DM: diabetes mellitus.

TABLE 3: Correlation between diabetes knowledge score and practices among patients $(n=500)$.

\begin{tabular}{lc}
\hline Variable & $r / p$ \\
\hline Knowledge score versus $\mathrm{HbA}_{1 \mathrm{c}}$ level & $-0.106 / 0.017^{*}$ \\
Knowledge score versus BMI & $0.007 / 0.874$ \\
Knowledge score versus WC & $0.042 / 0.345$ \\
\hline
\end{tabular}

${ }^{*}$ Correlation was significant at the 0.05 level (2-tailed); $\mathrm{HbA}_{1} \mathrm{c}$ : Hemoglobin $\mathrm{A}_{1} \mathrm{c}$; BMI: body mass index; WC: waist circumference.

$66 \%$ and $78 \%$ of newly diagnosed patients in our earlier study had average basic and technical knowledge on DM, respectively [4], and $68 \%$ of our nondiabetic study patients had average knowledge on DM [5]. A hospital-based study on knowledge, attitudes, and practices in India found that a good number of respondents had positive knowledge on and attitudes towards diabetes but the same cannot be said about practices [6]. Another study on knowledge and perceptions of diabetes in a semiurban Omani population found that subjects' level of knowledge was suboptimal [7]. A study in Pakistan among people with diabetes attending the department of Medicine, Khyber Teaching Hospital, Peshawar, found that the knowledge scores were low in most areas of diabetes care [9]. The mean diabetes knowledge score among Chinese patients with type 2 diabetes was good [10].

In the present study, our expectation could not reach our targeted level. The old diagnosed patients had the same level of knowledge as the newly diagnosed ones or nondiabetes subjects had. Further, we tried to find out the areas of deficient knowledge on DM among the patients. About $81 \%$ of the patients had good understanding of the pathophysiology of diabetes, although, around 90\% did not have correct knowledge on the risk factors of DM and ketoacidosis. Onethird did not know the targeted level of blood glucose, and more than half had no correct knowledge on hypos which is an important, dangerous symptom for DM patients. About $23 \%$ and $97 \%$ of the patients were unaware of the principles of dietary management and the food-exchange system, respectively. It is well known that improper dietary practice is one of the reasons for developing hypos.

Most $(81 \%)$ of our study patients were not aware of the importance of foot care. It is well known that noncare of the foot of diabetes patients may result in diabetic foot complications. People are known to have T2 DM usually in their mid-age, which thereafter begins to raise their blood glucose level with the duration of disease and patients might be fed up with the advice on treatment and modification of their lifestyle to be followed. Although it was hoped that approximately $70 \%$ of our study patients had fair or average knowledge of diabetes and considered diabetes a serious condition, with diet playing an important role in its control, they did not know or might not recall more and specific aspects of diabetes, such as risk factors of DM, food-exchange system, benefit of weighing food, and taking foot care. The data on knowledge relating to the above areas in our present study were much less or almost similar compared to the data reported in earlier studies $[4,5]$. Our results were not unlike those that have been reported elsewhere [7, 9, 11]. However, the Chinese study showed better results in these aspects [10].

Characteristics of our study patients correlated with their glycemic control and central obesity. We included those patients who were previously diagnosed and attended at least one diabetes education class. We assessed the association between the knowledge scores and the practices in terms of $\mathrm{HbA}_{1} \mathrm{c}, \mathrm{BMI}$, and WC; only the knowledge score and $\mathrm{HbA}_{1} \mathrm{c}$ had a significant $(p \leq 0.05)$ and negative association.

For more details, we run multivariable regression analysis. In our study, patients who were old, formally educated, female, and belonged to upper-middle and high-income groups tended to practice less in glycemic and weight management.

$\mathrm{HbA}_{1} \mathrm{c}, \mathrm{BMI}$, and WC values were significantly associated with old age, formal education, female gender, monthly income, and duration of DM but no significant relationship was found with other parameters. Around $70 \%$ of the aged people showed poor glycemic status and central obesity. Of the female patients, $80 \%$ were at high risk of obesity, and $85 \%$ from the high-income group were also at high risk of and had central obesity. The patients who had formal education were unaware of their glycemic status and also had poor compliance in blood glucose testing. Eighty-two percent of the patients who had diabetes for more than five years could not achieve their targeted level of glycemic status. Results of a study in India revealed that, with the increasing duration of diabetes, knowledge of patients also increases, 
TABLE 4: Multivariable regression analysis of $\mathrm{HbA}_{1} \mathrm{c}$ level as a dependent variable with other parameters among patients with type $2 \mathrm{DM}$ $(n=500)$.

\begin{tabular}{|c|c|c|c|c|c|}
\hline \multirow{2}{*}{ Variable } & \multirow{2}{*}{$\mathrm{B}^{1} \pm \mathrm{SE}$} & \multirow{2}{*}{ Beta $^{2}$} & \multirow{2}{*}{$p$ value } & \multicolumn{2}{|c|}{$95 \% \mathrm{CI}$ for $\mathrm{B}$} \\
\hline & & & & Lower & Upper \\
\hline Age & $0.471 \pm 0.201$ & 0.112 & 0.02 & 0.076 & 0.867 \\
\hline Gender & $-0.092 \pm 0.248$ & -0.027 & 0.712 & -0.579 & 0.396 \\
\hline Habitat & $-0.057 \pm 0.471$ & -0.006 & 0.903 & -0.982 & 0.868 \\
\hline Education & $-0.280 \pm 0.114$ & -0.138 & 0.014 & 0.503 & 0.056 \\
\hline Monthly income & $-0.036 \pm 0.106$ & -0.016 & 0.739 & -0.245 & 0.173 \\
\hline Occupation & $0.126 \pm 0.118$ & 0.076 & 0.286 & -0.105 & 0.356 \\
\hline Duration of DM & $0.513 \pm 0.162$ & 0.153 & 0.002 & 0.830 & 0.195 \\
\hline Family history of DM & $-0.101 \pm 0.169$ & -0.028 & 0.553 & -0.434 & 0.232 \\
\hline Total knowledge score & $-0.018 \pm 0.025$ & -0.040 & 0.464 & -0.068 & 0.031 \\
\hline
\end{tabular}

${ }^{1}$ Unstandardized sample regression coefficient. ${ }^{2}$ Standardized sample regression coefficient; adjusted $R^{2}=0.032$; overall model $F$-test, $p=0.004$.

TABLE 5: Multivariable regression analysis of BMI as a dependent variable with other parameters among patients with type 2 DM $(n=500)$.

\begin{tabular}{|c|c|c|c|c|c|}
\hline \multirow{2}{*}{ Variable } & \multirow{2}{*}{$\mathrm{B}^{1} \pm \mathrm{SE}$} & \multirow{2}{*}{ Beta $^{2}$} & \multirow{2}{*}{$p$ value } & \multicolumn{2}{|c|}{$95 \%$ CI for B } \\
\hline & & & & Lower & Upper \\
\hline Age & $0.344 \pm 0.462$ & 0.035 & 0.457 & 1.252 & 0.564 \\
\hline Gender & $-1.624 \pm 0.569$ & -0.205 & 0.005 & -2.743 & -0.505 \\
\hline Habitat & $1.193 \pm 1.08$ & 0.05 & 0.270 & -0.929 & 3.315 \\
\hline Education & $-0.139 \pm 0.261$ & -0.030 & 0.594 & -0.652 & 0.374 \\
\hline Monthly income & $0.570 \pm 0.244$ & 0.111 & 0.02 & 0.090 & 1.049 \\
\hline Occupation & $-0.177 \pm 0.270$ & -0.046 & 0.512 & -0.706 & 0.353 \\
\hline Duration of DM & $0.181 \pm 0.371$ & 0.023 & 0.625 & -0.547 & 0.910 \\
\hline Family history of DM & $-0.413 \pm 0.389$ & -0.05 & 0.289 & -1.177 & 0.351 \\
\hline Total knowledge score & $0.002 \pm 0.058$ & 0.002 & 0.966 & -0.111 & 0.116 \\
\hline
\end{tabular}

TABLE 6: Multivariable regression analysis of waist circumference as a dependent variable with other parameters among patients with type 2 $\operatorname{DM}(n=500)$.

\begin{tabular}{|c|c|c|c|c|c|}
\hline \multirow{2}{*}{ Variable } & \multirow{2}{*}{$\mathrm{B}^{1} \pm \mathrm{SE}$} & \multirow{2}{*}{ Beta $^{2}$} & \multirow{2}{*}{$p$ value } & \multicolumn{2}{|c|}{$95 \%$ CI for B } \\
\hline & & & & Lower & Upper \\
\hline Age & $3.490 \pm 1.134$ & 0.147 & 0.002 & 5.719 & 1.262 \\
\hline Gender & $0.612 \pm 1.397$ & 0.032 & 0.661 & -2.134 & 3.358 \\
\hline Habitat & $-0.253 \pm 2.65$ & -0.004 & 0.924 & -5.461 & 4.955 \\
\hline Education & $-1.025 \pm 0.641$ & -0.09 & 0.11 & -2.284 & 0.234 \\
\hline Monthly income & $1.728 \pm 0.599$ & 0.140 & 0.004 & 0.552 & 2.91 \\
\hline Occupation & $0.12 \pm 0.662$ & 0.013 & 0.856 & -1.180 & 1.420 \\
\hline Duration of DM & $0.399 \pm 0.910$ & 0.021 & 0.661 & -1.389 & 2.186 \\
\hline Family history of DM & $-0.282 \pm 0.954$ & -0.014 & 0.767 & -2.157 & 1.593 \\
\hline Total knowledge score & $0.101 \pm 0.141$ & 0.039 & 0.476 & -0.177 & 0.379 \\
\hline
\end{tabular}

which was reflected on their practices [6]. The opposite snapshot was found in our study. A Chinese study implied that knowledge on diabetes does not necessarily guarantee that people will achieve good glycemic control [10]. The same finding was found in our study where the total knowledge score did not show any significant effect on glycemic status in regression analysis. This indicates that sociodemographic characteristics need to be taken into consideration while developing educational programs for T2 DM patients and must be able to identify the potential barriers to learning. In our present study, the formally educated, wealthy patients were not aware of the disease which is a very unusual scenario. Another probable reason might be the "knowledge-action gap" between what people are taught to do and what they 
actually do. However, equally in a slow progressive disease such as diabetes, increasing $\mathrm{HbA}_{1} \mathrm{c}$ might be due to physiological reasons rather than noncompliance or knowledge deficits.

The results of the present study clearly indicate that old age, formal education, economic status, gender, and duration of DM are the most important factors associated with poor glycemic status and in developing central obesity.

In a study, it was recommended that repeated support of health education and strong motivation are essential to bring about positive changes in self-care practices in diabetes control [4]. The findings of our present study also support the above two recommendations, and based on these findings, we propose to develop patients' education program considering their literacy level and cultural needs. It is essential to understand the sociodemographic characteristics, beliefs and attitudes, motives, demands, and priorities of individuals to understand their compliance behavior. Although the tertiarycare hospital of the Diabetic Association of Bangladesh provides culturally appropriate structured education to its patients, the results of the present study suggest that policymakers should reconsider the strategy of the education program and find out the probable gaps which work as barriers to achieve the target level of healthy and disciplined lifestyle. These findings may indicate that, without patient empowerment, the present diabetes education program is largely ineffective for the better control of diabetes. For identifying gaps and to provide a truthful education program according to the patient's knowledge, perception, and skill, a longitudinal follow-up study is essential.

The present study has a couple of limitations. First, we used new samples from a tertiary-care hospital; however, if we would have used our previous ones [4], our comparison could have been more truthful. The knowledge and practices in terms of $\mathrm{HbA}_{1} \mathrm{c}, \mathrm{BMI}$, and WC relationship could not be significantly established in the study due to its crosssectional design nature. History on medication should have been included in the questionnaire of our study for more accurate assessment of glycemic status. The results should not, thus, be generalized for the whole diabetes population of Bangladesh also because of using convenient sampling technique and also because we were not able to incorporate all the underlined causal factors for identifying the gap due to the shortage of fund.

\section{Conclusions}

The results of the study state that type 2 diabetes patients are deficient of sufficient knowledge on the understanding of DM, risk factors of DM, targeted level of blood glucose, hypos, ketoacidosis, food exchange system, and basic rules of foot care; only knowledge score and $\mathrm{HbA}_{1} \mathrm{c}$ have a significant negative relationship, not other actions; risk factors for the patients' outcome include old age, female gender, higher education, high economic status, and duration of DM.

\section{Conflict of Interests}

The authors declare that they have no competing interests.

\section{Acknowledgments}

The authors highly acknowledge their respected colleague Mr. M. Shamsul Islam Khan, Advisor, Department of Library and In-Charge, English Foundation Course and Scientific Communication Course, Bangladesh University of Health Sciences, for his guidance in language editing. They also acknowledge the Diabetic Association of Bangladesh and thank their study patients.

\section{References}

[1] International Diabetes Association, Global Guideline for Type 2 Diabetes, Clinical Guidelines Task Force, Brussels, Belgium, 2012.

[2] K. Park, "Epidemiology of chronic noncommunicable diseases and conditions," in Park's Textbook of Preventive and Social Medicine, p. 341, Banarsidas Bhanot, Jabalpur, India, 20th edition, 2009.

[3] A. Hussain, M. A. Rahim, A. K. A. Khant, S. M. K. Ali, and S. Vaaler, "Type 2 diabetes in rural and urban population: diverse prevalence and associated risk factors in Bangladesh," Diabetic Medicine, vol. 22, no. 7, pp. 931-936, 2005.

[4] F. Saleh, S. J. Mumu, F. Ara, H. A. Begum, and L. Ali, "Knowledge and self-care practices regarding diabetes among newly diagnosed type 2 diabetics in Bangladesh: a cross-sectional study," BMC Public Health, vol. 12, no. 1, article 1112, 2012.

[5] S. J. Mumu, F. Saleh, F. Ara, M. R. Haque, and L. Ali, "Awareness regarding risk factors of type 2 diabetes among individuals attending a tertiary-care hospital in Bangladesh: a cross-sectional study," BMC Research Notes, vol. 7, article 599, 2014.

[6] C. K. P. Raj and M. M. Angadi, "Hospital-based KAP study on diabetes in Bijapur, Karnataka," Indian Journal of Medical Specialities, vol. 1, no. 2, pp. 80-83, 2010.

[7] M. A. Al-Shafaee, S. Al-Shukaili, S. G. A. Rizvi et al., "Knowledge and perceptions of diabetes in a semi-urban Omani population," BMC Public Health, vol. 8, article 249, 2008.

[8] K. Y. Tham, J. J. Y. Ong, D. K. L. Tan, and K. Y. How, "How much do diabetic patients know about diabetes mellitus and its complications?" Annals of the Academy of Medicine Singapore, vol. 33, no. 4, pp. 503-509, 2004.

[9] N. Gul, "Knowledge, attitudes and practices of type 2 diabetic patients," Journal of Ayub Medical College, Abbottabad, vol. 22, no. 3, pp. 128-131, 2010.

[10] X. He and H. J. Wharrad, "Diabetes knowledge and glycemic control among Chinese people with type 2 diabetes," International Nursing Review, vol. 54, no. 3, pp. 280-287, 2007.

[11] H. Baradaran and R. Knill-Jones, "Assessing the knowledge, attitudes and understanding of type 2 diabetes amongst ethnic groups in Glasgow, Scotland," Practical Diabetes International, vol. 21, no. 4, pp. 143-148, 2004.

[12] F. Saleh, S. J. Mumu, F. Ara, L. Ali, S. Hossain, and K. R. Ahmed, "Knowledge, attitude and practice of type 2 diabetic patients regarding obesity: study in a tertiary care hospital in Bangladesh," Journal of Public Health in Africa, vol. 3, no. 1, pp. 29-32, 2012.

[13] R. Mehrotra, S. Bajaj, D. Kumar, and K. J. Singh, "Influence of education and occupation on knowledge about diabetes control," National Medical Journal of India, vol. 13, no. 6, pp. 293-296, 2000. 
[14] K. Hawthorne and S. Tomlinson, "Pakistani moslems with type 2 diabetes mellitus: effect of sex, literacy skills, known diabetic complications and place of care on diabetic knowledge, reported self-monitoring management and glycaemic control," Diabetic Medicine, vol. 16, no. 7, pp. 591-597, 1999.

[15] A. Nicolucci, E. Ciccarone, A. Consoli et al., "Relationship between patient practice-oriented knowledge and metabolic control in intensively related type 1 diabetic patients: results of the validation of the knowledge and practices diabetes questionnaire," Diabetes, Nutrition \& Metabolism, vol. 13, no. 5, pp. 276-283, 2000.

[16] J. T. Fitzgerald, M. M. Funnell, G. E. Hess et al., "The reliability and validity of a brief diabetes knowledge test," Diabetes Care, vol. 21, no. 5, pp. 706-710, 1998.

[17] H. Mahtab, A. R. Khan, Z. A. Latif et al., Guidelines for Care of Type 2 Diabetes Mellitus in Bangladesh, BIRDEM Clinical Research Group, Dhaka, Bangladesh, 2003.

[18] A. N. M. N. Haque, By the Numbers: The Middle-Income Matrix, The Daily Star, 2007.

[19] WHO expert consultation, "Appropriate body-mass index for Asian populations and its implications for policy and intervention strategies," The Lancet, vol. 363, no. 9403, pp. 157-163, 2004. 


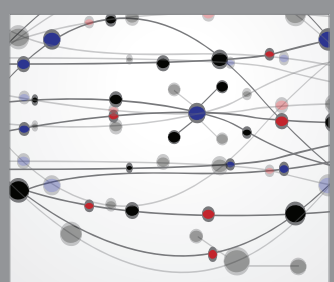

The Scientific World Journal
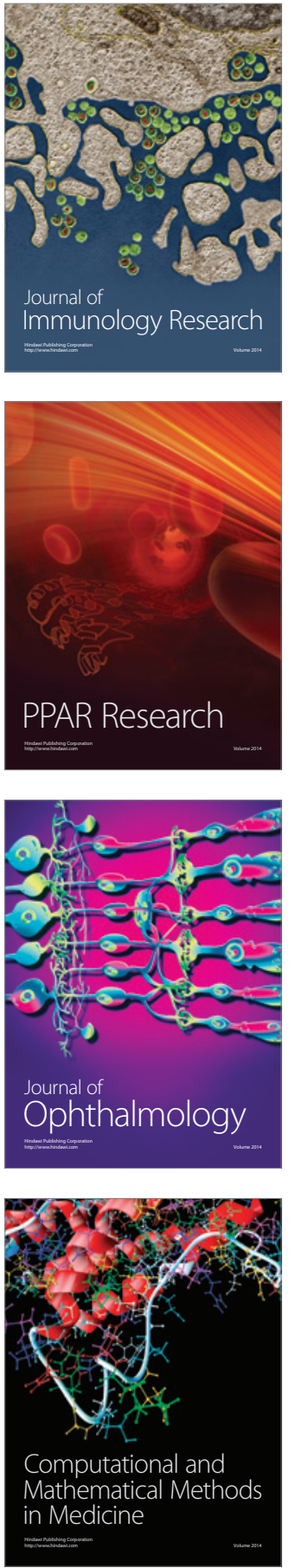

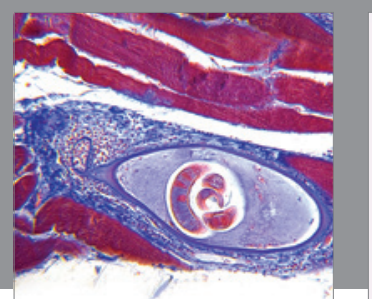

Gastroenterology Research and Practice

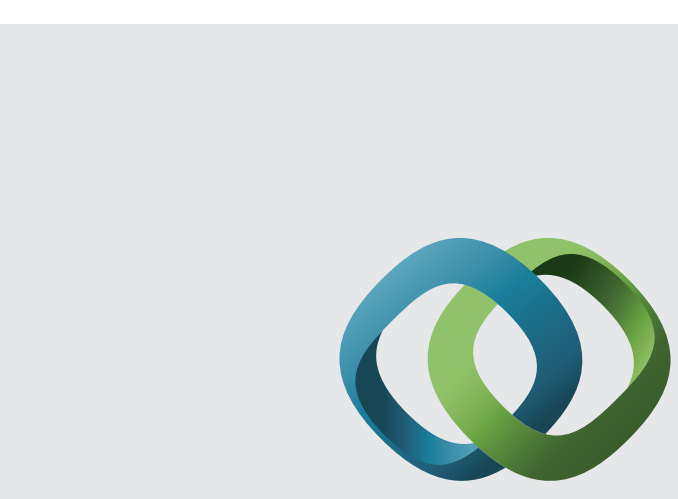

\section{Hindawi}

Submit your manuscripts at

http://www.hindawi.com
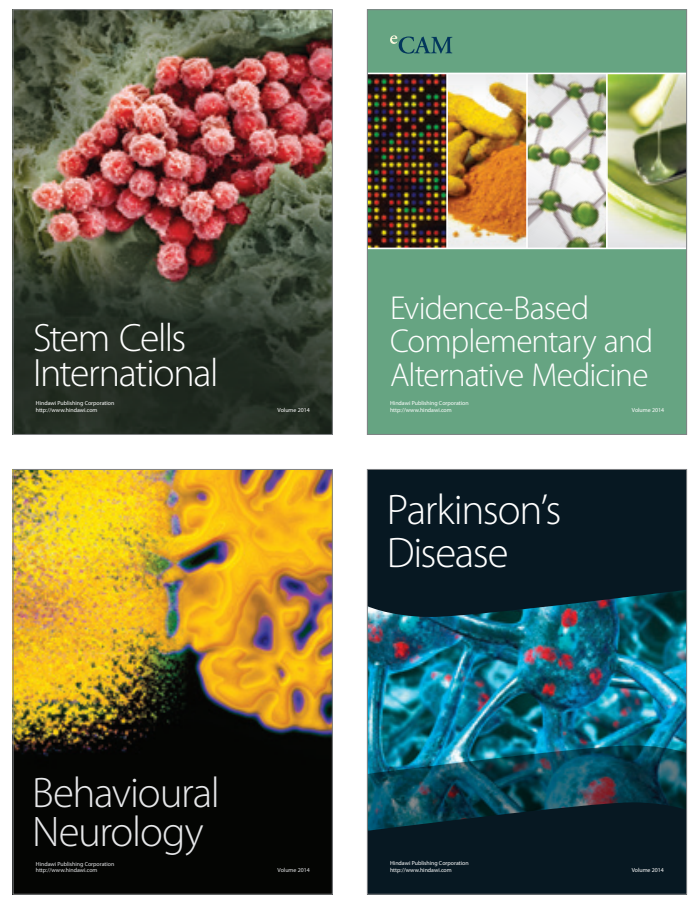
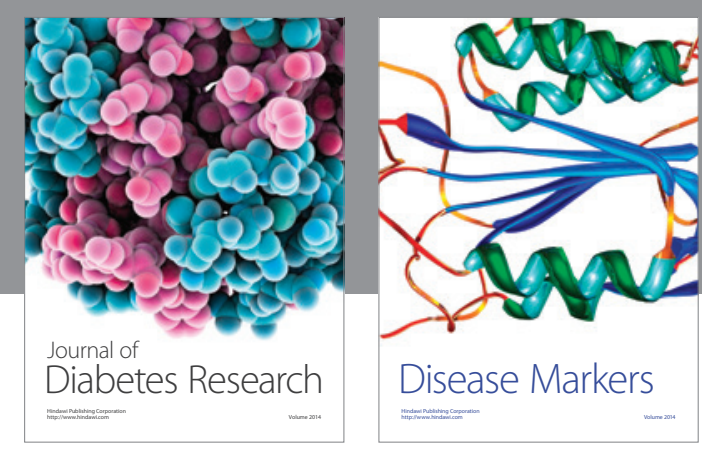

Disease Markers
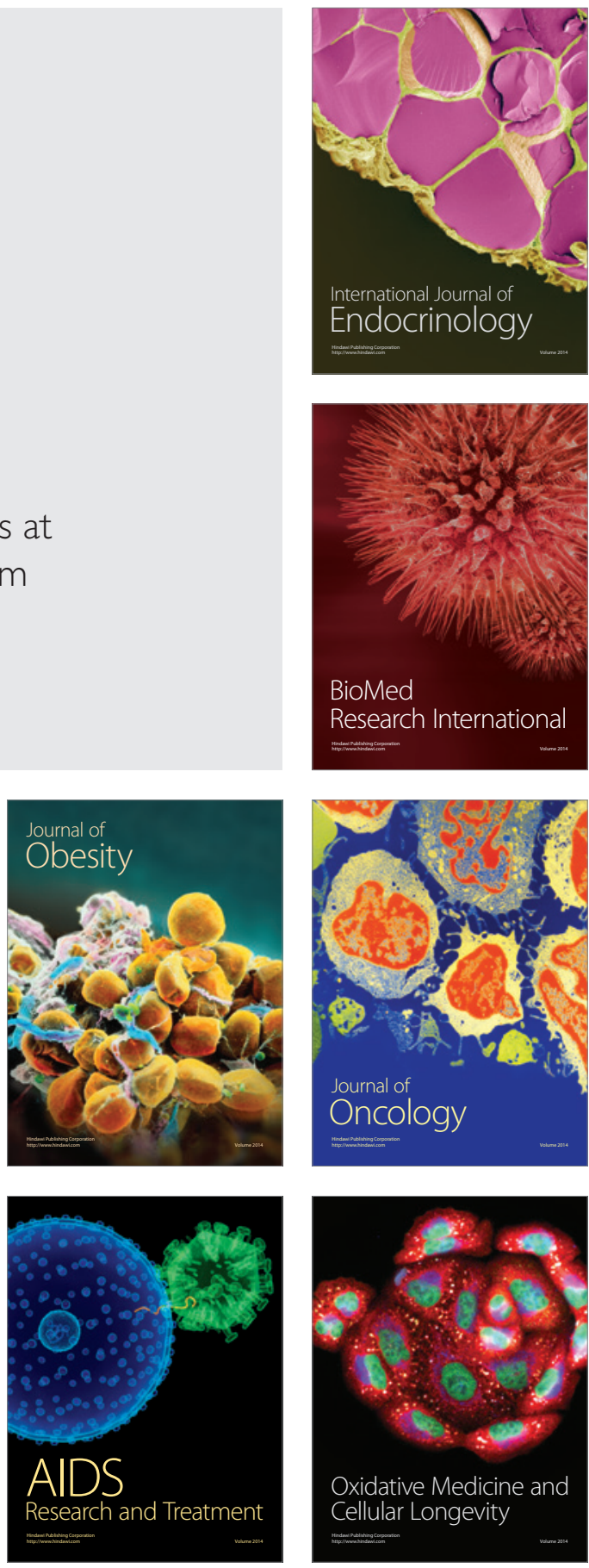